\title{
Demographic Change and Economic Growth: A Policy Perspective
}

Ahsan Butt, Hafiz Rizwan Ahmad and Abdul Jalil Khan ${ }^{1}$

\begin{abstract}
Many advanced countries are facing the problem of ageing population while many low-income countries still believe that controlling population may positively affect their economic growth. In this regard, this paper attempts to analyse effects of demographic factors on economic growth. A sample of top ten most populated countries in the world has been considered and panel 2GLS estimation technique has been applied to probe the effects of number of demographic and nondemographic variables on per capita GDP growth. The results reveal that per capita GDP growth rate is inversely associated with growth rate of population but is directly depended on life-expectancy, dependency ratio, gross domestic savings and labour force participation rate. The major finding is that although higher Population Growth Rate (PGR) may reduce per capita GDP growth rate initially but policies to strictly control the population growth may cause shortage of working age population (WAP) in short run and ageing society in long run. Therefore, rather pursuing the past policies of developed countries regarding control over PGR that have recently been reversed as well, Pakistan needs to develop human capital and labour productivity in rapidly ageing world.
\end{abstract}

Keywords: Demographic Change, Population Ageing, Economic Development.

JEL Classification: J11, J14, O15

\section{Introduction}

The relationship of population growth with economic development has been extensively studied. At the moment, the world is divided into two demographic regimes i.e. young and $\mathrm{old}^{2}$. On one hand, there is a group of developing countries that contains significant share of population less than 15 years age in contrast to many developed countries where issues of ageing and shrinking population have been emerged recently.

It is expected that changing age structure will be major driver of future policy formation in the world rapidly moving towards state of ageing population

1 The authors are Associate Lecturer at University of Narowal, and Assistant Professors at Department of Economics, Forman Christian College (A Chartered University), Lahore and, respectively. Corresponding author's Email: abduljalilkhan@fccollege.edu.pk

${ }^{2}$ Lutz et al. (2004) 
accompanied with declining level of fertility in most of the advance countries. Countries mainly populated with youth need to spend more on education and labour market development unlike ageing societies where a substantial share of budget is being allocated to the provisions of social security, pension funds and health facilities for old segment of population.

In future, an emerging gap between demand and supply of educated and skilful young labourer in developed countries will provide an opportunity for the countries like Pakistan to fill this gap by exporting surplus but skilful labourer and to effectively materialize the potential 'population dividend'.

The presence of demographic divide and contradictory population policies in developed and developing world lead towards a puzzle that what policy a country should opt in order to avoid the problems associated with demographic changes and to reap the fruits of demographic dividend in future. ${ }^{3}$ By analysing the effect of demographic changes on economic growth, the study will explore an appropriate policy measure for a country to optimize its population resource. The data set is comprised of ten most populated countries in the world for the period 1960-2017. These countries constitute around 60 percent of the world population, so a large share of the world population is covered in our data set. ${ }^{4}$

Rest of the paper includes objectives of the study in Section 2; in Section 3 literature review has been illustrated; analysis of changing age structure in selected countries is presented in Section 4; Section 5 describes theoretical framework; variables selection and estimation process are covered in Section 6; and results and conclusion are presented in Section 7.

\section{Objectives of the Study}

i. To analyse the changing age structure of ten most populated countries in the world.

ii. To evaluate the effect of demographic factors on economic growth.

\section{Literature Review}

Recently cross country analyses have been considered more relevant to evaluate how economic growth responds to demographic transition. Many researchers have analyzed the impact of varying share of working age population (WAP) on growth and development of the countries. Such as Bloom and

\footnotetext{
${ }^{3}$ Demographic dividend refers to the situation where an increase in economic growth is the outcome of increased share of WAP in a given country.

${ }^{4}$ United Nations: World Population Prospects, 2011.
} 
Williamson (1998); Bloom and Canning (2008); and Bloom and Finlay (2009) have found that rising ratio of WAP with respect to total population leads to increased growth in per capita income. Some other studies including Choudhry and Elhorst (2010); and Bloom et al. (2000) have assessed the difference between the rate of growth in WAP compare to total population and found a positive impact on per capita income growth rate in case when the growth rate of WAP is higher than the total population.

Prskawetzet al. (2007) also observes a positive effect of growth rate of WAP on labour productivity. The similar positive impact on Gross Domestic Product has been established in variety of other studies related to working population age such as Crenshaw et al. (1997); Bloom et al. (2000); Bloom and Canning (2008); Azomahou and Mishra (2008); and Bloom and Finlay (2009).

The wide-ranging literature has probed the linkages between demographic variables and GDP growth, especially to quantify the impact of young and old dependency ratios on economic growth. Crenshaw et al. (1997) observed that annual average percentage change in population age 15 or below has a significant inverse relationship and caused decline in growth rate of real GDP per capita. Whereas a study by Choudhry and Elhorst (2010) successfully incorporates both old and young dependency ratios into the analysis and provides the evidence that young dependency ratio has negative impact on growth of GDP per capita, however old dependency fails to establish any significant effect. A more concise outcome refers by Bloom and Williamson (1998) disclose that a 1 percent increase in young age dependency leads to decrease output growth per capita by 0.4 percent while old age dependency ratio shows no significant impact on growth potentials of per capita income.

Another study by Lindh and Malmberg (1999) analyses the nature and strength of association in changing structure of age with growth rate of GDP per worker in OECD countries and observes that old age population (aged above 65 years) remains primarily responsible in loss of per worker output growth potentials. However, no positive effect of young age population on labour productivity can be established. Prskawetzet al. (2007) also investigates that how much youth is dependent on growth of per capita output and detects the unfavourable outcomes for labour productivity.

Since the era of Malthusian perspective, the repercussions of population growth on economic growth has been considered an issue under population policy debate. The results of almost all of the recent research show an inverse relationship between population growth and the growth performance of the economy 
particularly in developing countries (Barlow 1994; Crenshaw et al., 1997; Bloom and Williamson 1998; Bloom et al., 2000; Prskawetzet al., 2007; Bloom and Canning 2008; Bloom and Finlay 2009)

The diverse findings regarding impact of population density on economic growth have been obtained in recent literature where it has been investigated thoroughly. Bloom et al. (2000) incorporates population density along the cost and inland density to probe its influence on economic growth. Interestingly, findings regarding population density along the coastal areas reveal a positive scenario and pronounce impact on economic growth rate whereas inland population density causes loss in economic growth (GDP growth rate per capita) ${ }^{5}$. Glover and Simon (1975) have observed that population density leads to enhance the expansion of infrastructure building (roads). They also prove a strong relationship between population density and density of paved-roads. Kelley and Schmidt (2005) try to capture the effect of population density on income growth per worker, but do not find any significant linkages between population density and economic growth.

Life expectancy is also one of the crucial variables in the analysis of demographic change and output growth. Life expectancy has been used as a proxy variable for good health in most of the cross-country analysis. Bloom and Williamson (1998); Bloom et al. (2000); Bloom and Canning (2008); Bloom et al. (2007); and Bloom and Finlay (2009) have revealed a direct impact of life expectancy on output per capita growth. Kelley and Schmidt (2005), Prskawetzet al. (2007) have also investigated the effect of life expectancy on growth rate of output per worker and again discovered the positive impact of higher life expectancy on labor productivity.

Some of the researchers have analyzed relationship between demographic variables and economic growth and have found it non-linear. An and Jeon (2006) identify non-linear relationship of demographic variables including share of young age population; proportion of old age population; youth and old dependency ratios with growth rate of per capita income. They also mention that countries with higher old age dependency ratio suffer more in terms of economic growth compared to countries with higher youth dependency ratio. Azomahou and Mishra (2008) study the OECD and non-OECD countries and discover a non-linear relationship of dynamic age structure with economic growth.

\footnotetext{
${ }^{5}$ Inland population density is defined as those areas that are more than 100 kilometres from the coast or from a navigable river that leads to the sea.
} 
Most demographers have found significantly direct impact of savings on economic development. An and Jeon (2006) observe a positive and significant impact of investment on per capita growth rate of GDP. Crenshaw et al. (1997) establishes that variation in gross domestic savings affects per capita GDP growth positively. Bloom and Williamson (1998) expose a direct but significant impact of average government saving rate on growth rate of per capita GDP.

Most of the researchers have found an insignificant impact of education on growth rate of per capita GDP. Bloom and Canning (2008) and Bloom et al. (2000) discover an insignificant impact of average years of schooling on GDP per capita growth rate. Bloom and Finlay (2009) probe the influence of average years of secondary schooling and reveal insignificant effect on GDP per capita growth. Kelley and Schmidt (2005) incorporate male education in their analysis and illustrate the same insignificant impact on per capita GDP growth.

Trade openness is also another non-demographic variable that has extensively been used by many demographers in their analysis of demographic change and economic growth. Mainly a significant impact on economic development has been observed with trade openness. Bloom and Williamson (1998); Bloom et al. (2000); Bloom and Canning (2008); and Bloom and Finlay (2009) disclose a positive and significant impact of trade openness (ratio of imports plus exports to GDP) on GDP per capita growth. Crenshaw et al. (1997) applies exports to GDP ratio as a proxy for openness and reveal the same positive and significant relationship with GDP growth per capita. Only An and Jeon (2006) has found an insignificant impact of trade openness on GDP per capita growth.

Demographers have also emphasized the importance of reaping the benefits from demographic dividend. In Pakistan, for example, Nayyab (2006) concludes that Pakistan is passing through once-in-a lifetime demographic phase, so there is a need to promote policies to improve education, health and labour market productivity.

\section{Changing Age Structures}

In order to analyse the changing age structure in selected countries, the ratio of working age population to total dependents have been calculated to reflect how much working age people are available per hundred dependents (young or old). Higher working age population identifies that more and more working age people are there to support the dependents. Table 1 shows that almost all the countries have experienced an increase in their working age population as compared to dependent population except Nigeria during 1950 to 2010. 
Table 1: Ratio of Working Age to Dependents

\begin{tabular}{lccc}
\hline Countries/ Years & $\mathbf{1 9 5 0}$ & $\mathbf{2 0 1 0}$ & $\mathbf{2 0 5 0}$ \\
\hline China & 163 & $260 \uparrow$ & $154 \downarrow$ \\
India & 137 & $181 \uparrow$ & $201 \uparrow$ \\
United States & 184 & $205 \uparrow$ & $164 \downarrow$ \\
Indonesia & 132 & $205 \uparrow$ & $185 \downarrow$ \\
Brazil & 125 & $198 \uparrow$ & $171 \downarrow$ \\
Pakistan & 131 & $152 \uparrow$ & $206 \uparrow$ \\
Bangladesh & 142 & $170 \uparrow$ & $206 \uparrow$ \\
Nigeria & 124 & $118 \downarrow$ & $202 \uparrow$ \\
Russian Federation & 185 & $258 \uparrow$ & $152 \downarrow$ \\
Japan & 148 & $176 \uparrow$ & $103 \downarrow$ \\
\hline
\end{tabular}

Source: Author's own calculations

However, in the near future, a decline in the ratio of working age to dependant population is projected in most of the countries except Pakistan, Bangladesh and Nigeria where the potential demographic dividend actually exist.

\section{Theoretical Relationship Between Variables of Study}

In order to achieve our second objective, i.e., to analyze how demographic change affects economic growth, this study presents the following expected relationships between dependant and independent variables of the study which are briefly summarized in Table 2

\subsection{Total Dependency Ratio and Economic Growth}

Ansley and Hoover (1958) dependency hypothesis shows that higher fertility rate leads to increase young population in a country. The young age structure of a country diverts resources from development expenditures to nondevelopmental consumption expenditures. So dependency ratio leads to retard economic growth

\subsection{Population Growth rate and Economic Growth}

The most complex relationship is observed between population and economic growth. On one hand, it depletes capital per capita available for existing labour, however population is considered to be a resource that generates new ideas that lead to enhance technological innovations on the other hand.

\subsection{Savings and Economic Growth}

During demographic transition, a significant rise in WAP is observed, so increase in savings may leads to enhance economic growth. 


\subsection{Education and Economic Growth}

Demographic transition starts with the decrease in mortality rate, it means that longevity increases in a country that is experiencing demographic transition. Higher life expectancy tends to change the behaviour of population regarding the investment in education. The return on education will be higher for a person that has a longer life i.e., the person will get high salary if he/she has higher level of education.

\subsection{Density and Economic Growth}

There exist different views concerning the effect of population density on economic growth. Pessimistic view argues that population density leads to congestion that has a negative effect on economic development. However, optimistic view argues that dense societies expand the demand for food items that put pressure for innovating new ways to increase output consequently encounter the increasing demand of food.

\subsection{Working Age Population and Economic Growth}

Demographic change provides a demographic dividend by increasing the WAP and decreasing dependency ratios (young and old). It is expected that a large share of WAP will increase savings and labor supply that will enhance economic growth.

\subsection{Life Expectancy and Economic Growth}

Higher longevity is an indication of good health and lower morbidity. Productivity of the labour will be high with good health. Increased life expectancy enhances output growth when people expect higher life expectancy resultantly they do not quit early from labour market and serve more than allocated time, hence they remain engaged for longer time period that rise output level ultimately.

Next section presents the empirical analysis performed by using the model developed by Barro and Sala-i-Martin (2004) to analyze the impact of demographic changes on per capita income.

\section{Estimation Technique and Selection of Variables}

We have used both Generalized Least Squares and Two Stage Least Squares methods for our empirical analysis. Simple Generalized Least Squares (GLS) estimation just considers unidirectional relationship between dependent and explanatory variables. However, there exist a well-known microeconomic theory of fertility determination and large amount of empirical literature supports that 
income growth not only influence the growth rate of population but also changes its structure (Bloom et al., 2000). So, in order to tackle the reverse causation between demographic variables and economic growth this study has re-estimated the growth model by using Panel Two Stage Generalized Least Squares estimation technique. Table 2 describes the details of dependent and independent variables.

Table 2: Description of Variables

\begin{tabular}{lll}
\hline Variables & Variable Description & Source \\
\hline GDP growth per capita & Annual \% increase in GDP per capita & WDI-17 \\
Density & Population per square kilometre & WDI-17 \\
RLFW & Ratio of labour force to WAP (15-64 years) & WDI-17 \\
Education & Total enrolment at tertiary level & WDI-17 \\
LE & Life expectancy at birth & WDI-17 \\
TDR (Total Dependency & (Population age less than 15 + Population age & WDI-17 \\
Ratio) & $\quad 65$ or older $\div$ population age 15 to 64) $\times 100$ & \\
PGR & Population growth $(\%$ annual) & WDI-17 \\
Gross Domestic Savings & Gross domestic savings (\% of GDP) & WDI-17 \\
Ratio of WAP to total & WAP $\div$ Total Population & WDI-17 \\
population & & WDI-17 \\
\hline
\end{tabular}

\section{Results of Empirical Analysis}

Table 3 shows the results of our generalized least squares and two stage generalized least squares analyses. The estimated coefficients in Two Stage Generalized Least Square are different from GLS both in terms of absolute values and significance level. In Two Stage Generalized Least Squares estimation, the estimated parameters of life expectancy, total dependency ratio, population growth rate, gross domestic savings and ratio of labour force to working age population are higher in magnitude that shows that the instruments used in estimation are valid and they have successfully controlled the reverse causality problem.

The coefficients of life expectancy is significant and positive and shows that one-year increase in longevity leads to increase GDP per capita growth rate by 0.12 points. These results are similar to earlier studies of Bloom and Canning (2008) and Bloom and Finlay (2009) who find a positive relationship between life expectancy and output per workers.

There are two important indicators, ratio of labour force to working age population and ratio of working age population to total population that have been included in the analysis. The first one shows the share of labour force in working age population while the second one shows the share of working age in total 
population. Our results disclose that the ratio of labour force to WAP is positive and significant in both the equations. However, after controlling for endogeneity, the ratio of WAP to total population turns out to be insignificant. This means that WAP can only be productive if they are willing to actively join the labour force of a country. This differentiates our study from earlier ones like that of Bloom and Williamson (1998); Bloom and Canning (2008); Bloom and Finlay (2009) who observe positive relationship between ratio of working age population to total population and growth in per capita income.

\section{Table 3: Effect of Demographic Change on GDP Per Capita Growth}

\begin{tabular}{lll}
\hline Coefficients & \multicolumn{1}{c}{ GLS } & \multicolumn{1}{c}{ 2GLS } \\
\hline Intercept & $-31.86124^{* * *}$ & $-37.19305^{* * *}$ \\
Log (Density) & 0.117319 & 0.008972 \\
Log (Education) & -0.81843 & -0.316882 \\
Life Expectancy & $0.07176^{* *}$ & $0.115574 * *$ \\
Total Dependency Ratio & $0.155204^{* * *}$ & $0.190046^{* *}$ \\
PGR & $-3.34864^{* * *}$ & $-3.580174 * *$ \\
Gross Domestic Savings & $0.148636^{* * *}$ & $0.167971 * * *$ \\
Growth Rate of Working Age & 0.109598 & -0.348363 \\
Log (RLFW) & $4.292198^{* * *}$ & $5.303937 * * *$ \\
Log (WAP to total population) & $-1.45585^{*}$ & -0.836134 \\
R squared & 0.81 & 0.79 \\
\hline Durbin Watson & 1.49 & 1.41 \\
\hline
\end{tabular}

Note: $*, * * * * *$ indicate $10 \%, 5 \%$ and $1 \%$ level of significance respectively.

The total dependency ratio has turned out to affect economic growth positively. This result is not coinciding with earlier studies of Crenshaw et al. (1997) and Choudhry and Elhorst (2010) who discover negative relationship between young dependency ratio and per capita income growth. This may be due to the fact that in our sample, total dependency ratio has a larger proportion of young people which generally affects positively by increasing share of WAP in future.

Our result is consistent with previous studies that have already been cited in literature where PGR affects GDP growth per capita significantly and negatively. The coefficient reveals that a one percent increase in PGR tends to decrease growth rate of GDP per capita by 3.58 percent.

From other variables, only gross domestic savings has a positive impact on economic growth. While the rest of the coefficients of density per square kilometre, 
education and growth rate of WAP have insignificant impact on per capita GDP in both equations.

\section{Conclusions and Policy Recommendations}

Our results show that demographic variables play an important role in explaining growth in per capita income, however, productivity of population and their active labour force participation are more important than a mere increase in the share of working age population. Keeping in view of the decreasing trend in the share of working age population in most of the advanced countries, Pakistan needs to put more efforts in the field of education and training to make our youth population productive and ready to fill the demand and supply gap of young labour force in coming future. 


\section{References}

An, C. B., \& Jeon, S. H. (2006). Demographic Change and Economic Growth: An Inverted-U Shape Relationship. Economic Letters, 92, 447-454.

Ansley, C. J., \& Hoover, E. M. (1958). Population Growth and Economic Development in Low Income Countries. New Jersey: Princeton University Press.

Azomahou, T., \& Mishra, T. (2008). Age Dynamics and Economic Growth: Revisiting the Nexus in a Non-parametric Setting. Economic Letters, 99, 67-71.

Barlow, R. (1994). Population Growth and Economic Growth: Some More Correlations. Population and Development Review 20(1), 153-165.

Barro, R. J., \& Sala-i-Martin, X. (2004). Economic Growth (2nd ed.). Massachusetts: The MIT Press.

Bloom, D. E., \& Canning, D. (2008). Global Demographic Change: Dimensions and Economic Significance. Population and Development Review, 34, 17-51.

Bloom, D. E., \& Finlay, J. E. (2009). Demographic Change and Economic Growth in Asia. Asian Economic Policy Review, 4, 45-64.

Bloom, D. E., \& Williamson, J. G. (1998). Demographic Transitions and Economic Miracles in Emerging Asia. The World Bank Economic Review, 12(3), 419-455.

Bloom, D. E., Canning, D., \& Malaney, P. N. (2000). Population Dynamics and Economic Growth in Asia. Population and Development Review, 26, 257-290.

Choudhry, M. T., \& Elhorst, J. P. (2010). Demographic Transition and Economic Growth in China, India and Pakistan. Economic Systems, 34, 218-236.

Crenshaw, E. M., Ameen, A. Z., \& Christenson, M. (1997). Population Dynamics and Economic Development: Age-Specific PGRs and Economic Growth in Developing Countries, 1965 to 1990 . American Sociogical Review, 62 (6), 974-984. 
Durr-e-Nayyab (2006). Demographic Dividend or Demographic Threat in Pakistan. PIDE Working Paper, 2006:10

Glover, D. R., \& Simon, J. L. (1975). The Effect of Population Density on Infrastructure: The Case Study of Road Building. Economic Development and Cultural Change, 23(3), 453-468.

Kelley, A. C., \& Schmidt, R. M. (2005). Evolution of Recent EconomicDemographic Modeling: A Synthesis. Journal of Population Economics, 18, 275-300.

Lindh, T., \& Malmberg, B. (1999). Age Structure Effects and Growth in the OECD, 1950-1990. Jorunal of Population Economics, 12(3), 431449.

Prskawetz, A., Kogel, T., Sanderson, W. C., \& Scherbov, S. (2007). The Effects of Age Structure on Economic Growth: An Application of Probabilistic Forecasting to India. International Journal of Forecasting, 23, 587-602. 